\title{
Effects of Oil Palm (Elais guineensis) Fruit Extracts on Glucose Uptake Activity of Muscle, Adipose and Liver Cells
}

\author{
S. FAEZ ${ }^{1 *}$, H. MUHAJIR ${ }^{2}$ I. AMIN ${ }^{3}$ AND A. ZAINAH ${ }^{4}$
}

\begin{abstract}
The effect of oil palm (Elaeis guineensis) fruit aqueous extract (OPF) on glucose uptake activity of three different cell lines was investigated. The cell lines were incubated with different concentrations of OPF to evaluate the stimulatory effect of OPF towards glucose uptake activity of L6 myotubes, 3T3F442A adipocytes and Chang liver cell line. The glucose uptake activities of all tested cells were enhanced in the presence of OPF extract (basal condition). Nevertheless in combination of OPF extract and $100 \mathrm{nM}$ insulin, the glucose uptake activity was only significantly enhanced in L6 myotubes and 3T3F442A adipocytes cell lines. The extracts enhanced the glucose uptake into cells through either insulin-mimetic or insulin-sensitizing property or combination of these two properties. It can be suggested that the OPF extract exerts its antihyperglycemic action partly by mediated glucose uptake into the glucose-responsive disposal cells, muscle, adipose and liver.
\end{abstract}

Hyperglycaemia in diabetic patients is reduced in a number of ways. One known mechanism to reduce hyperglycaemia is by glucose uptake into peripheral cells (muscle, adipocytes and liver) (Patel \& Mishra 2008). Glucose is taken into the cells through glucose transpoter (GLUTS). In the liver glucose, it is taken up through GLUT2 while GLUT4 play its role to take up glucose in adipocyte and muscle cells (Troy \& Glenn 2009). Insulin sensitizers like thiazolidinediones and metformin have been reported to improve insulin-mediated glucose uptake into peripheral cells (Zangeneh et al. 2003). They are oral antidiabetic drugs that usually prescribed to diabetic patients. However the drugs exert some adverse effect where those drugs were reported to cause gastrointestinal problems, peripheral edema and can cause weight gain (Arner 2003; Zangeneh et al. 2003). Thus these limitations have fuelled the search for alternative therapeutic agents for the treatment of diabetes mellitus.

Several plants have been identified to improve glucose uptake into peripheral cells. The antihyperglycemic properties of plants were reported to be associated with the polyphenolic and flavonoid content which can be found in various plants. Plants like Amomi semen (Kang \& Kim 2004) and Cortex Phellodendri (Ko et al. 2005) have been reported to enhance insulin-mediated glucose uptake activity into adipocytes cells. On the other hand Pterocarpus marsupium had been reported to enhance glucose uptake into L6 myotubes (Anandharajan et al. 2006). Those plants are believed to

\footnotetext{
${ }^{1}$ Department of Biotechnology, Kulliyah of Sciences, International Islamic University Malaysia, 25200 Indera Mahkota, Kuantan, Pahang, Malaysia

2 Department of Microbiology, Faculty of Biotechnology and Biomolecular Sciences, Universiti Putra Malaysia, 43400 Serdang, Selangor, Malaysia

${ }^{3}$ Department of Nutrition and Dietetics, Faculty of Medicine and Health Sciences, Universiti Putra Malaysia, 43400 Serdang, Selangor Malaysia

${ }^{4}$ Medical Technology Division, Malaysian Nuclear Agency, Bangi 43000 Kajang, Selangor, Malaysia

* Corresponding author (e-mail: faezsharif@gmail.com)
} 
enhance glucose uptake into peripheral cells through either mimicking or sensitizing insulin action (Jung et al. 2007). Plants with high phenolic antioxidant compounds exert high potential as supplements for improving blood glucose control and preventing long-term complications among diabetics (Gallegher et al. 2003).

The oil palm fruit is planted abundantly throughout Malaysia. The fruit has been extensively researched for its health and nutritional properties, including antioxidant activities, cholesterol lowering, anticancer effects and protection against cardiovascular diseases (Sundram et al. 2003). The fruits are also reported to contain a significant degree of antioxidant polyphenolic compounds (Sundram et al. 2003; Neo et al. 2010). Nevertheless the antidiabetic effects of oil palm fruits on stimulating glucose uptake activity are yet to be known. Therefore in the present study the ability of oil palm fruit extracts (OPF) to stimulate glucose uptake into peripheral (muscle, adipose and liver) cells were evaluated. The L6 myotubes, 3T3F442A adipocytes and Chang liver cell line was used as the model of the system.

\section{MATERIALS AND METHODS}

\section{Sampling and Sample Preparation}

The oil palm fruit, E. guineensis, was collected from the Universiti Putra Malaysia Agriculture Park. Ripe oil palm fruits were harvested from trees and used as the fresh sample. The fresh oil palm fruits were scraped into thin flakes and dried in oven overnight at $40^{\circ} \mathrm{C}$. The dried fruits then were ground into small particles and the oil was removed with hexane (Merck, Germany) by using the Soxhlet method $\left(45^{\circ} \mathrm{C}\right.$, 8 h). Following removal of oil, the OPF was extracted according to the method described by Wang and Halliwell (2001). Briefly $1 \mathrm{~g}$ of dried de-oiled oil palm mesocarp was mixed with $40 \mathrm{ml}$ of $60 \%$ aqueous ethanol (Merck, Germany). Subsequently, $5 \mathrm{ml}$ of $6 \mathrm{M} \mathrm{HCl}$
(Merck, Germany) was added into the mixture prior to reflux. After refluxing for $2 \mathrm{~h}$, the extract was cooled, filtered, and standardized to $50 \mathrm{ml}$ with $60 \%$ ethanol. Then the solvent was removed using a rotary evaporator. Finally the OPF was preserved by freeze drying.

\section{Cell Line Maintenance}

In the evaluation of glucose uptake activity, three cell lines were used (L6 myotubes, 3T3F442A adipocytes and Chang liver cells) as the model of the glucose uptake system. L6 myotubes and 3T3F442A adipocytes were maintained in Dulbecco's Modified Eagle Medium (DMEM) while Chang liver cells were maintained in medium Roswell Park Memorial Institute (RPMI). The complete culture medium was done by addition of $10 \%(\mathrm{v} / \mathrm{v})$ fetal bovine serum (FBS) and 1\% (v/v) antibiotic solution. The cell lines were incubated and humidified with $5 \% \mathrm{CO}_{2}$ at $37^{\circ} \mathrm{C}$ condition. Following sub-confluences $(70 \%-80 \%)$ cultures were split using $0.25 \%$ Trypsin to $1: 3$. After that the cells were centrifuged for $5 \mathrm{~min}$ at 10 000 r.p.m. and the pellets were suspended again into culture medium until reaching confluency. The L6 myoblasts were induced to differentiate into myotubes by reducing the FBS in the complete culture medium from $10 \%$ to $2 \%$ (Ziyou et al. 2009). The cells were maintained with this medium for 4-6 days post-confluence. Along the period the cells were observed and the extent of differentiation was established by observing multinucleation of cells. The 3T3F442A fibroblast-like cells were spontaneously differentiated into adipocytes upon reaching confluency. The presence of viscous media in each well confirmed the extent of differentiation as free fatty acids were produced by the cells and secreted into the media.

\section{Evaluation of Glucose Uptake Activity of OPF Extract}

The cells were seeded into 12 -well plate at the concentration of $2 \times 10^{5}$ cells per well. The cells 
then were left overnight to allow attachment. After the cells were attached on the following day, they were washed with serum-free medium thrice. Then the cells were incubated with the same medium for two hours. After the starvation period, the cells were then washed with Kreb's-Ringer bicarbonate buffer (KRB) thrice. Then the cells were pre-incubated for 30 min with various concentration of OPF extract. Metformin and rosiglitazone maleate were used as positive control. After $30 \mathrm{~min}$ of incubation, $500 \mu \mathrm{l}$ of 2 -deoxy- $\left[{ }^{3} \mathrm{H}\right]$-glucose $1 \mu \mathrm{Ci} / \mathrm{ml}$ diluted $0.1 \mathrm{mM}$ glucose was added to each well except the blanks to initiate the glucose uptake reaction. The reaction was allowed to occur for $60 \mathrm{~min}$. Subsequently the cells were washed trice with ice-cold KRB buffer. Then $0.1 \%$ sodium dodecyl sulphate dissolved in $0.1 \mathrm{M}$ phosphate buffer $\mathrm{pH} 7.4$ was added to solubilize the cells. Then the mixture of each well was transferred into the scintillated cocktail and 15 $\mathrm{ml}$ of scintillated cocktail, Ultima Gold ${ }^{\mathrm{TM}}$ was added. Finally the radioactivities incorporated into the L6 myotubes which indicated the glucose uptake activity were measured using Liquid Scintillation Counter (Hewlett Packard, USA).

\section{Statistical Analysis}

Data were expressed as mean \pm standard deviation. One-way ANOVA (GraphPad Prism 5) were used for analysis and groups were considered significantly different at the 5\% significance level $(\mathrm{p}<0.05)$. Dunnet post-hoc test was done if a significant value was obtained for ANOVA.

\section{RESULTS AND DISCUSSIONS}

Cell lines are homogenous culture of cells. Due to their homogeneity, the cell lines become the best choice to study the effects of an agent on insulin activity compared to isolated cells or tissues which are mixed in nature. Furthermore, cell lines are more stable and have longer lifespan compared to the isolated cells (Parthasarathy et al. 2009). In the present study, three cell lines were used to study the effects of OPF extract on glucose uptake activity. The cell lines used include L6 myotubes, 3T3F442A adipocytes and Chang liver cells. A previous report has found that L6 myotube was the best-characterized cellular model of skeletal muscle to study the glucose uptake activity by GLUT4 translocation (Patel \& Mishra 2008). The 3T3F442A adipocyte on the other hand has been widely used to study the effects of an insulinotropic agent on glucose uptake activity into adipocytes (Sakurai et al., 2004). Meanwhile the Chang liver cell is one of the models used widely to study the glucose transports in the liver besides HepG2 and H4IIE (Rengarajan et al. 2007). All models of cell lines used in this study showed the ability to enhance glucose uptake activity when treated with OPF extract at particular concentrations (Figures 1-3). This observation indicated that there was a possibility that the antidiabetic compounds were present in the OPF extract. The compounds might have the potential to regulate hyperglycaemia through the enhancement of glucose disposal into muscle, adipose and liver cells. However purification of the compounds was not conducted in the present study. Therefore further experimentations are needed to be carried out to evaluate the exact compounds which may be responsible to regulate the mechanism by which this disposal is mediated.

Plant extracts may potentiate the glucose uptake into cells through insulin-mimetic or insulin sensitizing properties. These properties of plants were reported to be associated with the flavonoids content which can be found in various plants. For example, a flavonoids found in grapefruit namely naringenin, has been shown to increase basal glucose uptake in L6 myotubes which is comparable to $100 \mathrm{nM}$ insulin (Zygmunt et al. 2010). On the other hand, the grape seed contains procyanidins which is reported to have insulin-mimetic effect during stimulating glucose uptake into 3T3L1 adipocytes cells (Pinent et al. 2004). Glucose is 
taken into the cells through glucose transpoter (GLUTS). In the liver glucose it is taken up through GLUT2 while GLUT4 plays its role to take up glucose in adipocyte and muscle cells (Troy \& Glenn 2009). The GLUT4 is located inside the cells and its translocation to cell membrane to facilitate glucose transport into the cells are sensitize with the presence of insulin. In contrast GLUT2 is located in the cell membrane and facilitate glucose transport into cells without the need of insulin. GLUT2 can sensor the presence of glucose independently since they have high capacity and low affinity (high $\mathrm{K}_{\mathrm{m}}$ value, $15 \mathrm{mM}-20 \mathrm{mM}$ ) for glucose. The high $\mathrm{K}_{\mathrm{m}}$ value allows for glucose sensing where the rate of glucose uptake is proportional to blood glucose level (Li et al. 2007). Nevertheless according to the previous report the presence of insulin can also enhance the glucose uptake activity in Chang liver cells (Satake et al. 2002). Our present data are in accordance with the previous reports where insulin $100 \mathrm{nM}$ alone significantly enhanced glucose uptake activity in all types of cells evaluated (Figures 1-3). The same concentration of insulin was used to mediate the glucose uptake activity of OPF extract in L6 myotubes, 3T3F442A adipocytes and Chang liver cells. Furthermore according to the previous report, the $100 \mathrm{nM}$ of insulin concentration has also been widely used to mediate the glucose disposals into cells (Sakurai et al. 2004). Nevertheless in the treatment using combination of OPF and $100 \mathrm{nM}$ insulin, only the L6 myotubes and 3T3F4424A adipocytes showed a significant enhancement in the glucose uptake activity. The glucose uptake activity of Chang liver cell was not significantly enhanced in the presence of both OPF and $100 \mathrm{nM}$ insulin (Figure 3). The Chang liver cell mediated the glucose uptake through GLUT2 where insulin was not the core factors in their mechanism to mediate glucose uptake compared to GLUT4 which required insulin to promote glucose transportation into the muscle and adipose cells. Therefore the difference of functional GLUT protein involved in the translocation of glucose into the liver cells might explain the results obtained in the previous study (Li et al. 2007).

The mechanisms underlie the insulinmimetic and insulin-sensitizing property of the OPF extract was not elucidated in the presence study. However the insulin-like or insulin-mimetic activity of a plant has been

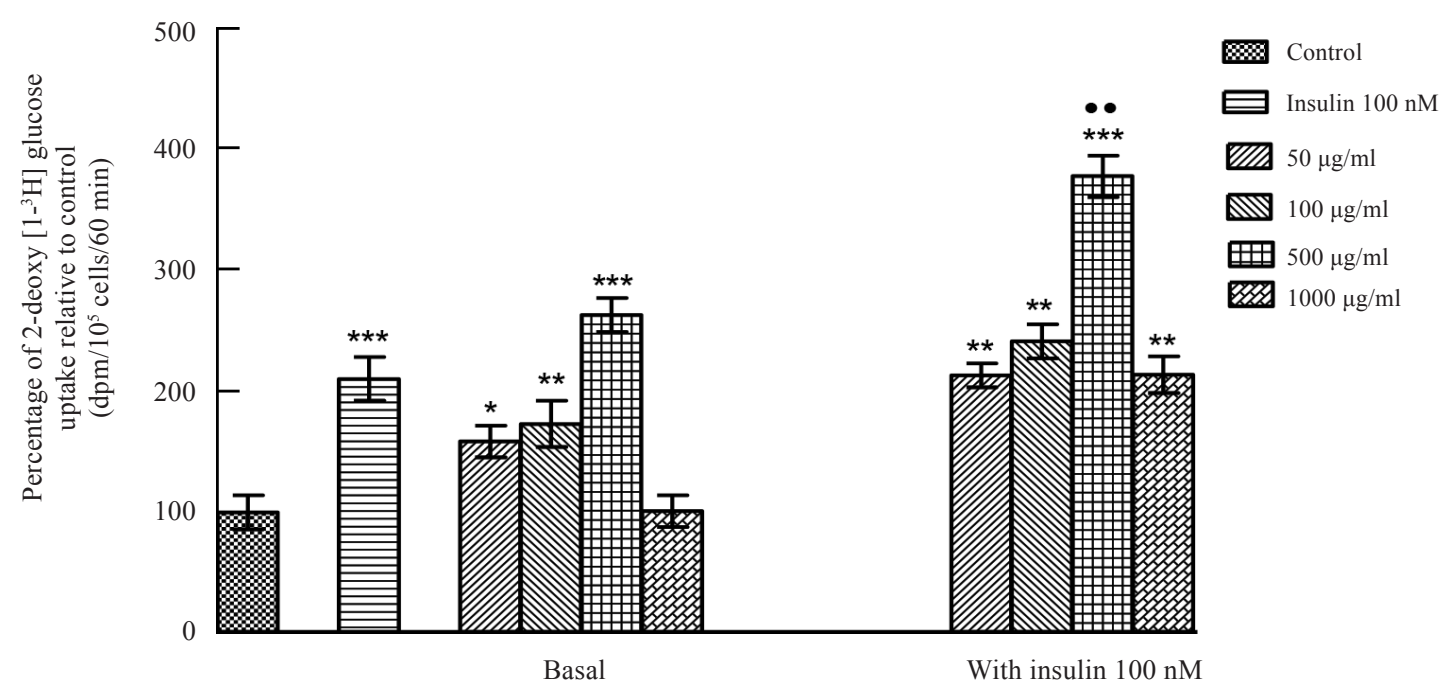

Figure 1. Effect of OPF extract on basal and insulin-mediated glucose uptake activity of L6 myotubes. Values represent the means $\pm S . D .{ }^{*} p<0.05,{ }^{* *} p<0.01$ and ${ }^{* * *} p<0.001$ compared with control. $\bullet \bullet p<01$ compared to $100 \mathrm{nM}$ insulin alone. 
evaluated previously in several plants. An example is the fanugreek seed. The fenugreek seed extract has been reported to mediate the glucose uptake activity into liver and adipocytes through the activation of tyrosine phosphorylation of $ß$-subunit of insulin receptor.
This activation subsequently enhanced tyrosine phosphorylation of insulin receptor substrate-1 (IRS-1) and p85 subunit of phosphatidylinositol3-kinase (PI3-kinase) which leads to glucose uptake by these cells (Vijayakumar et al. 2005). The insulin sensitizing activity has

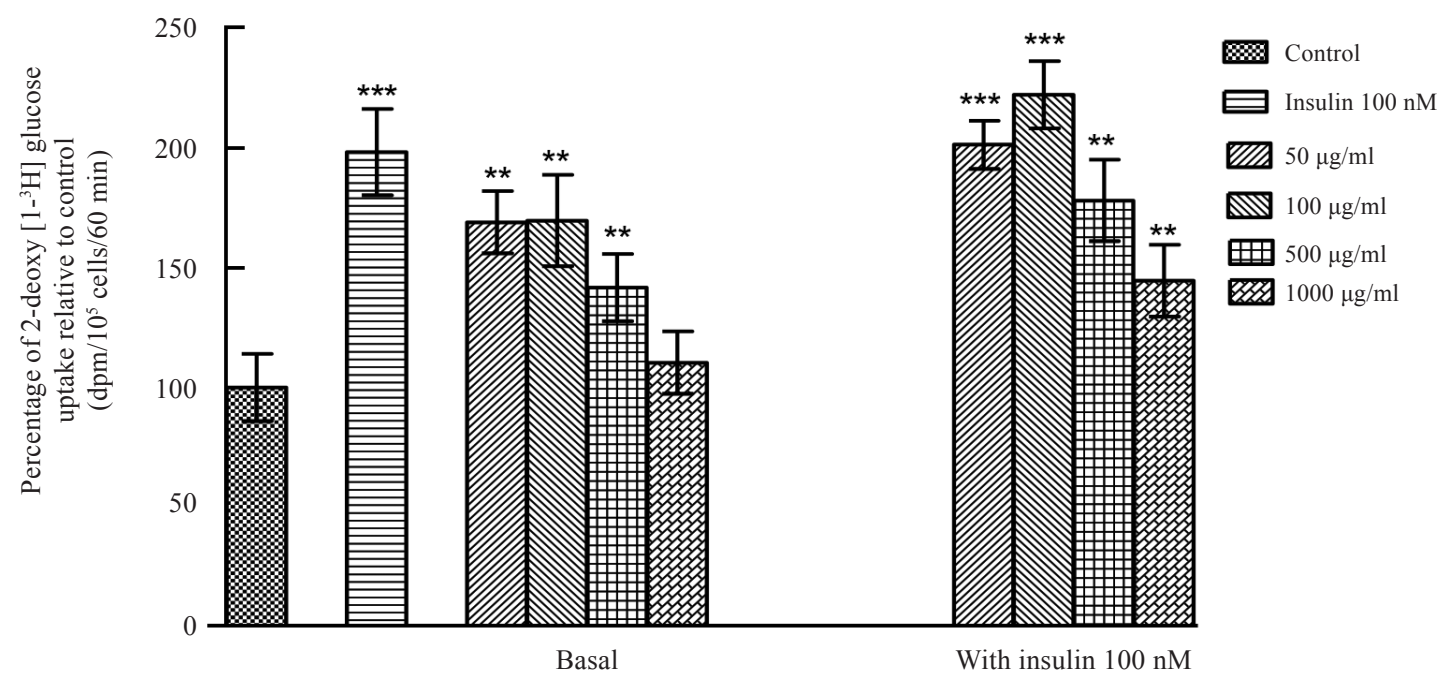

Figure 2. Effect of OPF extract on basal and insulin-mediated glucose uptake activity of $3 T 3 F 442 \mathrm{~A}$ adipocytes. Values represent the means $\pm S . D .{ }^{* *} p<0.01$ and ${ }^{* * *} p<0.001$ compared with control.

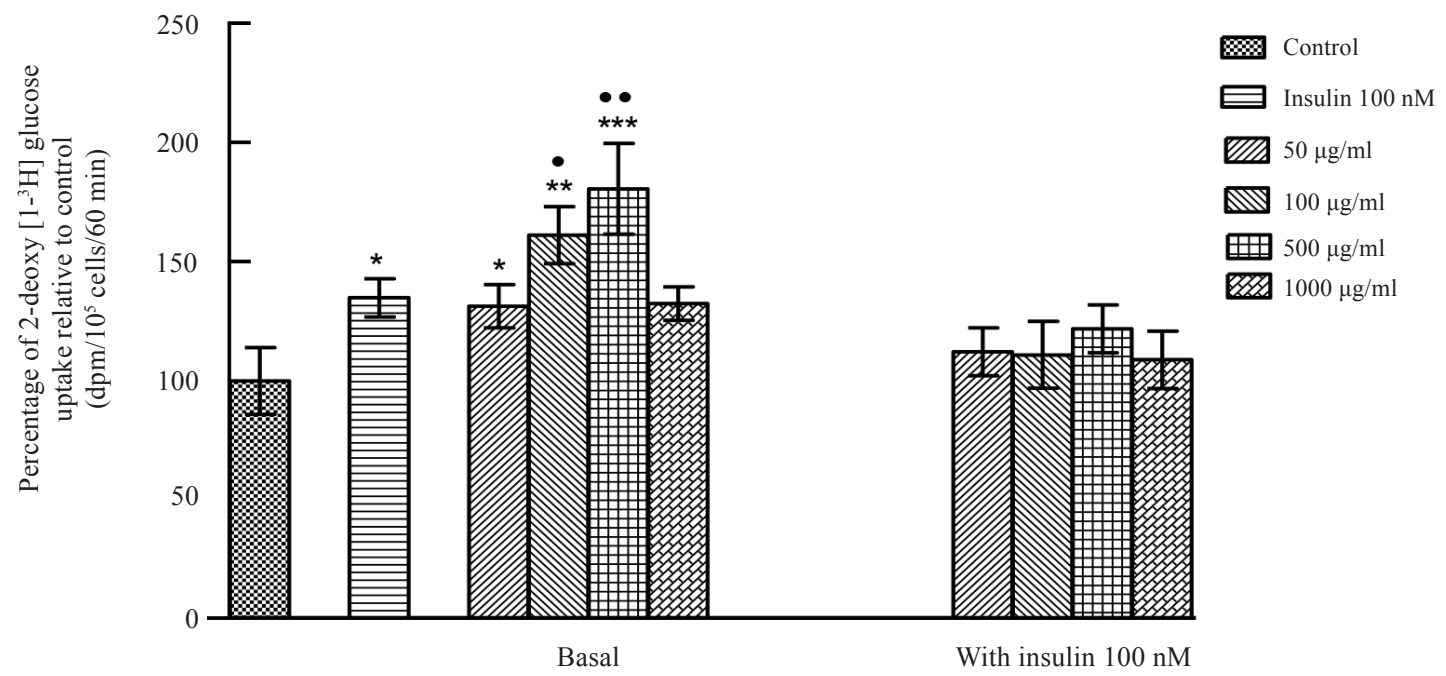

Figure 3. Effect of OPF extract on basal and insulin-mediated glucose uptake activity of Chang liver cells. Values represent the means $\pm S . D .{ }^{*} p<0.05,{ }^{* *} p<0.01$ and ${ }^{* * *} p<0.001$ compared with control. $\bullet p<0.05$ and $\bullet \bullet p<0.01$ compared to $100 \mathrm{nM}$ insulin alone. 
been previously reported in several plants like Campsis grandiflora (Jung et al. 2007) and miltiorrihiza Bunge. They were reported to enhance the tyrosine phosphorylation of insulin receptor and activation of downstream kinase. Therefore there are possibilities that OPF extract exert the insulin-mimetic and insulin-sensitizing properties through the mentioned mechanisms. However further evaluation are needed to be carried out to confirm this suggestion.

\section{Date of submission: September 2014}

Date of acceptance: November 2014

\section{REFERENCES}

Anandharajan, R, Pathmanathana, K, Shankernarayanan, NP, Vishwakarmab, RA \& Balakrishna, A 2005, 'Upregulation of GLUT4 and PPAR $\gamma$ by an isoflavone from Pterocarpus marsupium on L6myotubes: A possible mechanism of action', Journal of Ethnopharmacology, vol. 97, pp. 253-260.

Arner, P 2003, 'The adipocyte in insulin resistance: key molecules and the impact of the Thiazolidinediones', Trends in Endocrinology and Metabolism, vol. 14, no. 3, pp. 137-144.

Gallagher, AM, Flatt, PR, Duffy, G \& Abdel-Wahab, YHA 2003, 'The effects of tradisional antidiabetic plants in vitro glucose diffusion', Nutrition Research, vol. 23, pp. 413-424.

Jung, SH, Ha, YJ, Shim, E K, Choi, SY, Jin, JL, Yun-Choi, HS \& Lee, JR 2007, ' Insulin mimetic and insulin sensitizing activities of tanshinones, diterpine compounds of the root of Salvia miltiorrhiza Bunge, Phytomedicine, vol. 16, pp. 327-335.

Kang, Y \& Kim, YH 2004, 'Glucose uptakestimulatory activity of Amomi semen in 3T3-L1 adipocytes', Journal of Ethnopharmacology, vol. 92, pp. 103-105.

Ko, BS, Choi, SB, Park, SK, Jang, JS, Kim, YE \& Park, S 2005, 'Insulin-sensitizing and insulinotropic action of Berberin from Cortidis Rizhoma, Biological \& Pharmaceutical Bulletin, vol. 28, no. 8, pp. 1431-1437.

Li, R, Thorens, B \& Loeken, MR 2007, ' Expression on the gene encoding the high $\mathrm{Km}$ glucose transporter 2 by the early post-implantation mouse embryo is essential for neural tube defects associated with diabetic embryopathy', Diabetologia, vol. 503, pp. 682-689.

Neo, YP, Aziz, A, Tan, C P \& Tan, YA 2010, 'Phenolic acid analysis and antioxidant activity assessment of oil palm E. Guineensis fruit extracts', Food Chemistry, vol. 122, pp. 353-359.

Parthasarathy, C, Renuka, VN \& Balasubramaniam, K 2009, 'Sex steroids enhance insulin receptors and glucose oxidation in Chang liver cells', Clinica Chimica Acta, vol. 399, vols. 1-2, pp. 49-53.

Patel, MB \& Mishra, SH 2008, 'Cell line in diabetic research: a review', Pharmacognosy Review, vol. 2, no. 4, pp. 188-205.

Pinent, M, Blay, M, Blade, MC, Salvado, MJ, Arola, L \& Ardevol, A 2004, 'Grape seed derived procyanidins have an antihyperglycemic effect in streptozotocin-induced diabetic rats and insulinomimetic activity in insulin sensitive cell lines', Endocrinology, vol. 145, no. 11, pp. 4985-4990.

Rengarajan, S, Parthasarathy, C, Anitha, M \& Balasubramaniam, K 2007, 'Diethyl phthalate impairs insulin binding and glucose oxidation in Chang liver cells', Toxicology in Vitro, vol. 21, pp. 99-102.

Sakurai, K, Kawazuma, M, Adachi, T, Harigaya, T, Saito, Y, Hashimoto, N \& Mori, C 2004, 'Bisphenol A affects glucose transport in mouse 3T3F442A adipocytes', British Journal of Pharmacology, vol. 141, no. 2, pp. 209-214.

Satake, S, Moore, MC, Igawa, K, Converse, M, Farmer, B, Neal, DW \& Cherrington, AD 2002, 'Direct and indirect effects of insulin on glucose uptake and storage by the liver', Diabetes, vol. 51, no. 6, pp. 1663-1671.

Sundram, K, Sambarthamurti, R \& Tan, YA 2003, 'Palm fruit chemistry and nutrition', Asia Pacific J. Clin. Nutr., vol. 12, no. 3, pp. 355-362.

Troy, LM \& Glenn, KM 2009, 'Skeletal muscle glucose uptake during excercise: a focus on reactive oxygen species and nitric oxide signalling', Life, vol. 615, pp. 479-484.

Vijayakumar, MV, Singh, S, Chhipa, RR \& Bhat, MK 2005 , 'The hypoglycaemic activity of fenugreek seed extract is mediated through the stimulation of an insulin signalling pathway', British Journal of Pharmacology, vol. 146, pp. 41-48. 
Wang, H \& Helliwell, K 2001 Determination of flavonols in green and black tea leaves and green tea infusion by high performance liquid chromatography', Food Research International, vol. 34, pp. 223-227.

Zangeneh, F, Kudva, YC \& Basu, A 2003, 'Insulin sensitizers', Mayo Clinic Proceedings, vol. 784, pp. 471-479.

Ziyou, C, Xiulan, C, Bingwen, L, Sung, KP, Tao, $\mathrm{X}$, Zhensheng, X, Peng, X, Junjie, H, Haiying,
H, John, RY \& Fuquan, Y 2009 'Preliminary quantitative profile of differential expression between rat L6 myoblast and myotubes by stable isotope labelling by amino acids in cell culture', Proteomics, vol. 95, pp. 1274-1292.

Zygmunt, K, Faubert, B, MacNeil, J \& Tsiani, E 2010, 'Naringenin, a citrus flavonoid, increases muscle cell glucose uptake via AMPK, 'Biochemical and Biophysical Research Communications, vol. 398, no. 2, pp. 178-183. 